\title{
Solvent-free direct $\alpha$-alkylation of ketones by alcohols catalyzed by nickel supported on silica-alumina
}

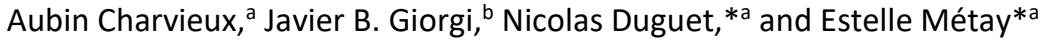

The $\alpha$-alkylation of acetophenone with benzyl alcohol through borrowing hydrogen has been studied using nickel catalysis. $\mathrm{Ni} / \mathrm{SiO}_{2}-\mathrm{Al}_{2} \mathrm{O}_{3}$ was found to be the best catalyst for this transformation and the corresponding alkylated acetophenone was obtained with $93 \%$ isolated yield. Following the objectives of clean and sustainable chemistry, the reaction occurs under solvent-free conditions and requires only a catalytic amount of base. This protocol was next applied to a wide range of ketones and alcohols and the desired products were isolated with $18-86 \%$ yields ( 26 examples). The recovery and recyclability of the nickel catalyst was also investigated and it was found to be active over 5 runs without significant loss of activity. Surprisingly, the active catalyst appears to include an amorphous nickel hydroxide layer.

\section{Introduction}

$\alpha$-Alkylation of ketone enolates with electrophilic agents is a common method to create C-C bonds. ${ }^{1-2}$ However, such reactions use (pseudo)halides which are often toxic and produce stoichiometric waste salts. Alternatively, alcohols can be efficiently used for the $\alpha$-alkylation of ketones catalyzed by transition-metals through a borrowing-hydrogen mechanism. ${ }^{3-}$ ${ }^{6}$ This methodology exhibits high atom economy, as water is the sole co-product. Homogeneous catalysts with precious metals such as Ru, ${ }^{7-11} \mathrm{Ir},{ }^{12-16} \mathrm{Rh},{ }^{17} \mathrm{Os},{ }^{18} \mathrm{Au},{ }^{19}$ and $\mathrm{Re}^{20}$ have been widely studied for the $\alpha$-alkylation of ketones with alcohols. Although used in low loadings, these organometallic complexes are expensive. Recently, homogeneous catalysts have been developed with more abundant metals such as $\mathrm{Fe}^{, 21-22} \mathrm{Mn},{ }^{23}$ and $\mathrm{Co},{ }^{24}$ though still using very specific ligands. Recyclable heterogeneous catalysts offer a greener approach for the $\alpha$ alkylation of ketones with alcohols. Heterogeneous palladium has been widely used for this transformation in the form of $\mathrm{Pd} / \mathrm{C}^{25-26} \mathrm{Pd} / \mathrm{AlO}(\mathrm{OH}),{ }^{27}$ nanopalladium liganded to viologen polymers, ${ }^{28}$ palladium loaded titanate nanotubes, ${ }^{29}$ bimetallic $\mathrm{Au}-\mathrm{Pd}$ nanoparticles ${ }^{30}$ and $\mathrm{Pd} / \mathrm{MgO}-\mathrm{Al}_{2} \mathrm{O}_{3} \cdot{ }^{31}$ Supported ruthenium $^{32}$ and copper on hydrotalcite ${ }^{33}$ have also been reported as catalysts for this process. Though some work previously cited take advantage of the basic support of the catalyst, these reactions generally require a large excess of base (up to $300 \mathrm{~mol} \%$ ), a solvent and hydrogen acceptor in some cases. Only two groups reported the use of nickel catalyst for $\alpha$ alkylation of ketones with alcohols. Yus et al. used nickel nanoparticles (from nickel chloride) for this process, without any base. ${ }^{34-35}$ However, this reaction requires a stoichiometric amount of nickel nanoparticles. Sugitani et al. filed a patent mentioning the use of supported nickel catalysts but the nature of the catalyst used was not precisely described. ${ }^{36}$ In this context, we report herein a solvent-free $\alpha$-alkylation of ketones by alcohols with recyclable nickel supported on silica-alumina through the borrowing-hydrogen strategy.

\section{Results and discussion}

The $\alpha$-alkylation of acetophenone 1a with benzyl alcohol 2a has been chosen as a reaction model for the initial investigation. A range of heterogeneous metal-based catalysts was tested at $175^{\circ} \mathrm{C}$ under solvent-free conditions using $\mathrm{K}_{3} \mathrm{PO}_{4}(10$ mol\%) as external base (Table 1 ). Considering that precious metals are expensive and that the metal loading on the support is quite low (5 or $10 \mathrm{wt} \%$ ), the catalyst loading was set at $2.5 \mathrm{~mol} \%$ in order to allow a good stirring. Noble metals such as $\mathrm{Ru} / \mathrm{C}, \mathrm{Ru} / \mathrm{Al}_{2} \mathrm{O}_{3}$, $\mathrm{Pd} / \mathrm{C}$ and $\mathrm{Pt} / \mathrm{C}$ allowed moderate to good conversion but low to moderate yields (21-61\%, Table 1 , entries $1-4)$. Non-precious metals were next considered and tested at $20 \mathrm{~mol} \%$.

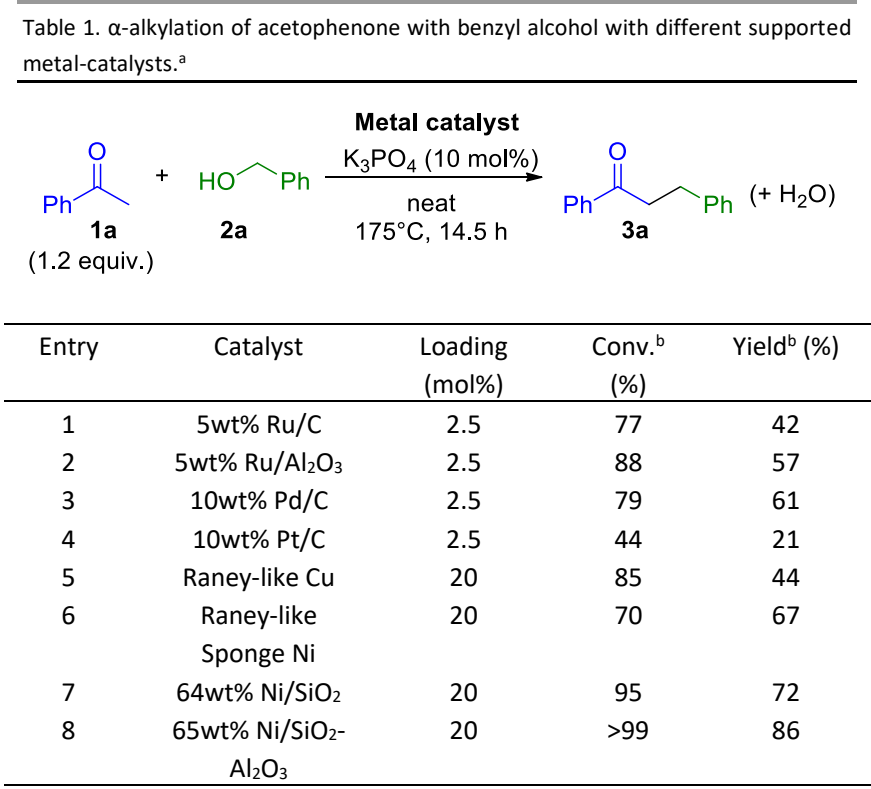

a Reaction conditions: 1a (11.6 mmol, 1.2 equiv.), 2a (9.7 mmol), supported metal catalyst, $\mathrm{K}_{3} \mathrm{PO}_{4}(10 \mathrm{~mol} \%)$, neat, $175^{\circ} \mathrm{C}, 14.5 \mathrm{~h}$. ${ }^{\mathrm{b}}$ Conversion of $2 \mathrm{a}$ and yield of 3 a were determined by ${ }^{1} \mathrm{H}$ NMR with mesitylene as internal standard.

Raney-like copper and sponge nickel catalysts afforded moderate to good results, with 44 and $67 \%$ yield, respectively (Table 1, entries 5-6).Nickel on silica gave a slightly better yield (Table 1, entry 7). Finally, using nickel supported on silicaalumina, the reaction afforded the desired $\alpha$-alkylated ketone $3 a$ in $86 \%$ yield, thus showing the importance of the silicaalumina support (Table 1 , entry 8 ). Consequently, this catalyst was chosen for further optimization. Several bases were next screened for this reaction (Table 2). The yields were low with sodium acetate and magnesium oxide (Table 2, entries 1 and 2 ). Similarly, the reaction with potassium hydroxide or potassium 
tert-butoxide afforded low yields and moderate conversions (Table 2, entries 3 and 4).

Table 2. $\alpha$-alkylation of acetophenone with benzyl alcohol catalyzed by Ni/SiO${ }_{2}-\mathrm{Al}_{2} \mathrm{O}_{3}$ with different bases. ${ }^{\text {a }}$

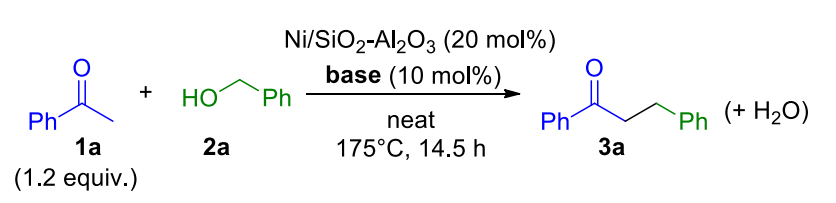

\begin{tabular}{cccc}
\hline Entry & Base & Conv. $^{\mathrm{b}}(\%)$ & Yield $^{\mathrm{b}}(\%)$ \\
\hline 1 & $\mathrm{NaOAc}$ & 36 & 25 \\
2 & $\mathrm{MgO}$ & 73 & 11 \\
3 & $\mathrm{KOH}$ & 60 & 23 \\
4 & ${ }^{\mathrm{BuOK}}$ & 77 & 42 \\
5 & $\mathrm{~K}_{2} \mathrm{CO}_{3}$ & $>99$ & 78 \\
6 & $\mathrm{CS}_{2} \mathrm{CO}_{3}$ & 68 & 18 \\
7 & $\mathrm{~K}_{3} \mathrm{PO}_{4}$ & $>99$ & 86 \\
\hline
\end{tabular}

a Reaction conditions: $1 \mathrm{a}$ ( $11.6 \mathrm{mmol}, 1.2$ equiv.), $2 \mathrm{a}(9.7 \mathrm{mmol}), 65 \mathrm{wt} \% \mathrm{Ni} / \mathrm{SiO}_{2}$ $\mathrm{Al}_{2} \mathrm{O}_{3}(20 \mathrm{~mol} \%)$, base $(10 \mathrm{~mol} \%)$, neat, $175^{\circ} \mathrm{C}, 14.5 \mathrm{~h}$. ${ }^{\mathrm{b}}$ Conversion of $2 \mathrm{a}$ and yield of $3 a$ were determined by ${ }^{1} \mathrm{H}$ NMR with mesitylene as internal standard.

Important disparities were observed when using carbonate bases. If a good yield (78\%) could be obtained using potassium carbonate, cesium carbonate only gave poor results (Table 2, entries 5 and 6$)$. The best result was obtained with potassium phosphate ( 10 mol\%), affording $86 \%$ yield of 3a (Table 2 , entry 7). Potassium phosphate was therefore selected as the best base for this reaction.

Other parameters were next studied (Table 3). As expected, the yield dropped when the catalyst loading was decreased at 15 mol\% (Table 3, entry 1), and could not be improved after prolonged time. Decrease or increase of the base loading also resulted in a decline of the yield, showing that a $10 \mathrm{~mol} \%$ base loading is optimal in these conditions (Table 3, entries 2-3). Inversion of the starting material ratio decreased the yield: an excess of the ketone is apparently necessary, contrary to the previously cited reactions in the literature (Table 3, entry 4). At least 1.2 equivalents of $1 \mathbf{a}$ are needed to obtain a good yield: a reduction at 1.1 equivalents of 1 a results in a loss of $16 \%$ yield (Table 3, entry 5). Several blank experiments were carried out in order to verify that both the catalyst and the base are essential for this reaction (Table 3, entries 6-8). When $\mathrm{K}_{3} \mathrm{PO}_{4}$ was used in the absence of catalyst, $3 \mathbf{3}$ was obtained in poor yield (Table 3, entry 6 ). This result shows that $\mathrm{K}_{3} \mathrm{PO}_{4}$ could act as a mediocre catalyst for this reaction, in the same fashion than $\mathrm{NaOH}$ does in the Guerbet reaction. ${ }^{37}$ When the reaction was carried out with the catalyst but without base, a similar yield of 3a was obtained (Table 3, entry 7). However, the conversion was quite high, indicating that other reactions occurred under these conditions. ${ }^{1} \mathrm{H}$ NMR analysis of the crude reaction mixture revealed a higher quantity of benzaldehyde ( $6 \%$ yield) than in all other conditions (traces of benzaldehyde).
Table 3. Optimization of loadings, starting material ratio, temperature and time. ${ }^{\mathrm{a}}$

\begin{tabular}{|c|c|c|c|c|}
\hline $\mathrm{Ph}_{1 \mathrm{a}}^{\mathrm{O}}$ & $\begin{array}{l}\mathrm{HO} \\
\mathbf{2 a}\end{array}$ & $\begin{array}{c}\mathrm{Ni} / \mathrm{SiO}_{2}-\mathrm{Al}_{2} \mathrm{O}_{3} \\
\mathrm{~K}_{3} \mathrm{PO}_{4}\end{array}$ & $\mathrm{Ph}_{3 \mathbf{a}}^{\stackrel{\mathrm{O}}{\mathrm{H}}}$ & $\mathrm{Ph}\left(+\mathrm{H}_{2} \mathrm{O}\right)$ \\
\hline Entry & $\begin{array}{c}\mathrm{Ni} / \mathrm{SiO}_{2}-\mathrm{Al}_{2} \mathrm{O}_{3} \\
(\mathrm{~mol} \%)\end{array}$ & $\begin{array}{c}\mathrm{K}_{3} \mathrm{PO}_{4} \\
(\mathrm{~mol} \%)\end{array}$ & Conv. $^{b}(\%)$ & Yield $^{\mathrm{b}}(\%)$ \\
\hline 1 & 15 & 10 & 95 & 72 \\
\hline 2 & 20 & 5 & 89 & 69 \\
\hline 3 & 20 & 15 & 86 & 62 \\
\hline $4^{[c]}$ & 20 & 10 & $79^{[\mathrm{d}]}$ & 57 \\
\hline $5^{[\mathrm{e}]}$ & 20 & 10 & 90 & 70 \\
\hline 6 & 0 & 10 & 69 & 22 \\
\hline 7 & 20 & 0 & 89 & 21 \\
\hline 8 & 0 & 0 & 2 & 0 \\
\hline$g^{[f]}$ & 20 & 10 & 59 & 39 \\
\hline $10^{[\mathrm{g}]}$ & 20 & 10 & $>99$ & $93(93)^{[\mathrm{h}]}$ \\
\hline
\end{tabular}

a Reaction conditions: 1a (11.6 mmol, 1.2 equiv.), 2a $(9.7 \mathrm{mmol})$, $65 \mathrm{wt} \% \mathrm{Ni} / \mathrm{SiO}_{2}-\mathrm{Al}_{2} \mathrm{O}_{3}, \mathrm{~K}_{3} \mathrm{PO}_{4}$, neat, $175^{\circ} \mathrm{C}, 14.5 \mathrm{~h}$. ${ }^{\mathrm{b}}$ Conversion of $2 \mathrm{a}$ and yield of $3 a$ were determined by ${ }^{1} \mathrm{H}$ NMR with mesitylene as internal standard. ${ }^{c}$ 1a:2a molar ratio is 1:1.2. d Conversion of 1 a determined by ${ }^{1} \mathrm{H}$ NMR with mesitylene as internal standard. e 1a:2a molar ratio is 1.1:1. ${ }^{f}$ Reaction temperature was $150^{\circ} \mathrm{C}$. ${ }^{g}$ Reaction time was $24 \mathrm{~h} .{ }^{\mathrm{h}}$ Isolated yield in parenthesis.<smiles>O=C(CC(CC(=O)c1ccccc1)c1ccccc1)c1ccccc1</smiles>

b)

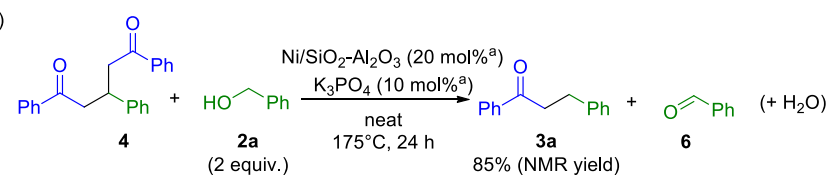

Scheme 1. a) Formation of 4. b) Reaction between $\mathbf{4}$ and benzyl alcohol 2a (a: mol\% with respect to benzyl alcohol).

This shows that the aldolisation step is much slower without base, as one could expect. No reaction was observed without catalyst and base, thus confirming that both catalyst and base are needed for this reaction (Table 3 , entry 8 ). The decrease of the temperature to $150^{\circ} \mathrm{C}$ afforded moderate conversion and yield (Table 3, entry 9). Finally, the reaction time was increased to 24 hours (Table 3, entry 10). Satisfyingly, the conversion was complete and the alkylated product 3a was isolated with $93 \%$ yield. During the optimization of this reaction, the formation of a secondary product 4 was observed. NMR and mass spectroscopy analyses indicated that 4 could be the product of the 1,4-addition of acetophenone 1 a on chalcone $\mathbf{5}$ (Scheme 1a). Interestingly, this product was observed at low conversion and disappeared completely at total conversion, thus suggesting that its formation was reversible. To verify this hypothesis, 4 was engaged in reaction with benzyl alcohol 2a, $\mathrm{Ni} / \mathrm{SiO}_{2}-\mathrm{Al}_{2} \mathrm{O}_{3}$ and $\mathrm{K}_{3} \mathrm{PO}_{4}$ (Scheme $1 \mathrm{~b}$ ). Two equivalents of benzyl alcohol $2 \mathrm{a}$ with respect to 4 are required in this case, one equivalent being used to reduce chalcone $\mathbf{5}$ via hydrogen-transfer. Under these conditions, 3a was successfully formed with $85 \%$ NMR yield. We proposed a simplified mechanism according the observed 
intermediates (Scheme 2). Benzyl alcohol 2a is dehydrogenated into benzaldehyde $\boldsymbol{6}$ by the nickel catalyst. The chalcone 5 is then formed by the aldolisation/crotonisation catalyst by $\mathrm{K}_{3} \mathrm{PO}_{4}$ with acetophenone 1a and $\mathbf{6}$. Chalcone $\mathbf{5}$ is then hydrogenated by the nickel catalyst giving the desired product 3a. Benzaldehyde $\mathbf{6}$ and chalcone $\mathbf{5}$ were usually observed in low amounts. Two main side reactions catalyzed by nickel have been identified, leading to the formation of toluene and benzene. Toluene was formed by hydrogenolysis of $\mathbf{2 a}$. Decarbonylation of benzaldehyde gave benzene and carbon monoxide. This reaction is well known and has been recently reported with $\mathrm{Ni}(\mathrm{COD})_{2}{ }^{38}$ These side reactions are mainly responsible for the difference between the conversions and the yields of the reported results.

The scope of $\alpha$-alkylation of acetophenone with respect to the alcohols was then investigated under the optimized conditions (Scheme 3).

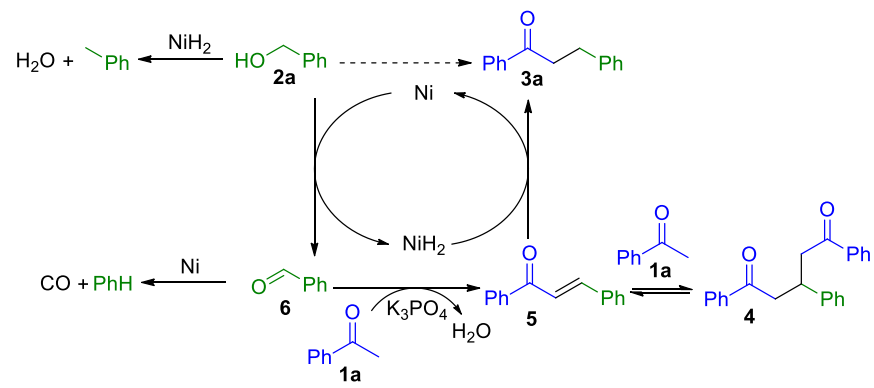

Scheme 2. Simplified mechanism based on the observed reaction intermediates.
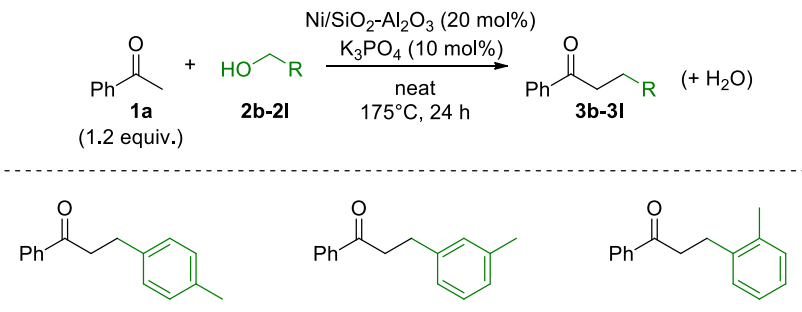

3b: $78 \%$ yield $(71 \%)$

3c: $74 \%$ yield $(67 \%)$

3d: $71 \%$ yield $(61 \%)$

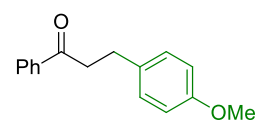

3e: $86 \%$ yield $(86 \%)$

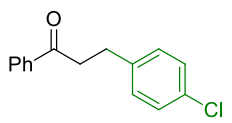

3h: $34 \%$ yield $(18 \%)$

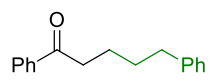

3k: $56 \%$ yield $(39 \%)$

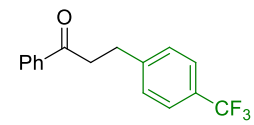

3f: $52 \%$ yield $(52 \%)$<smiles>CC(C)(C)CCC(=O)c1ccccc1</smiles>

3i: $33 \%$ yield $(24 \%)$

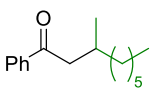

3l: $13 \%$ yield

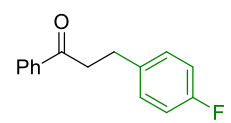

3g: $61 \%$ yield $(55 \%)$<smiles>CC(C)CCC(=O)c1ccccc1</smiles>

$3 j: 52 \%$ yield $(52 \%)$

3m: $61 \%$ yield $^{\mathrm{a}}\left(56 \%^{\mathrm{a}}\right)$

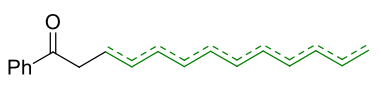

Scheme 3. Alkylation of acetophenone with various alcohols. Reaction conditions: 1a (11.6 mmol, 1.2 equiv.), $2 \mathrm{~b}-2 \mathrm{l}$ ( $9.7 \mathrm{mmol}$ ), $65 \mathrm{wt} \% \mathrm{Ni} / \mathrm{SiO}_{2}-\mathrm{Al}_{2} \mathrm{O}_{3}(20 \mathrm{~mol} \%), \mathrm{K}_{3} \mathrm{PO}_{4}(10$ mol\%), neat, $175^{\circ} \mathrm{C}, 24 \mathrm{~h}$. Yields of $3 \mathrm{~b}-3 \mathrm{~m}$ were determined by ${ }^{1} \mathrm{H}$ NMR with mesitylene as internal standard, isolated yield in parentheses. ${ }^{\mathrm{a} C o m b i n e d}$ yields of unsaturated isomers (only one $\mathrm{C}=\mathrm{C}$ bond) and saturated species.
The reaction with benzyl alcohols bearing para-electron-donating groups such as methyl or methoxy afforded good yields ( $\mathbf{3 b}$ and $\mathbf{3 e}$ ). With methyl benzyl alcohols, the position of methyl group has little impact on the yield but a slight decrease of the yield was observed from para to ortho position (from $\mathbf{3 b}$ to $\mathbf{3 d}$ ). An electron withdrawing-group such as trifluoromethyl gave moderate yield (3f). Benzyl alcohols with para-halogen group gave mixed results: fluorine group gave the desired product in moderate yield $(\mathbf{3 g})$ whereas a low yield was obtained with chlorine group ( $3 \mathrm{~h})$. This can be explained by the dechlorination of both chloro-benzyl alcohol and the desired product by the catalyst. Reactions with aliphatic alcohols were also carried out. With neopentyl alcohol, a low yield was observed (3i), certainly due to its relatively low boiling point. Other alcohols such as 1-octanol or 3-phenylpropyl alcohol gave moderate yields ( $\mathbf{3} \mathbf{j}$ and 3k), which could be explained by the lower reactivity of aliphatic aldehydes compared to aromatic ones. 2-Octanol gave a very low yield (3I). In that case, 2-octanone was observed as the major product and was obtained with $61 \%$ yield. In order to evaluate the compatibility of this reaction with an alcohol containing a remoted double bond, 10-undecen-1-ol was tested. The $\mathrm{C}=\mathrm{C}$ bond mainly underwent isomerization and/or reduction and a mixture of the corresponding products was obtained. The unsaturated products with terminal $\mathrm{C}=\mathrm{C}$ bond $(4 \%)$ or internal $\mathrm{C}=\mathrm{C}$ bond $(36 \%)$ were mainly formed, along with the saturated species (16\%).

The conditions were then applied to the alkylation of a range of ketones by benzyl alcohol (Scheme 4).

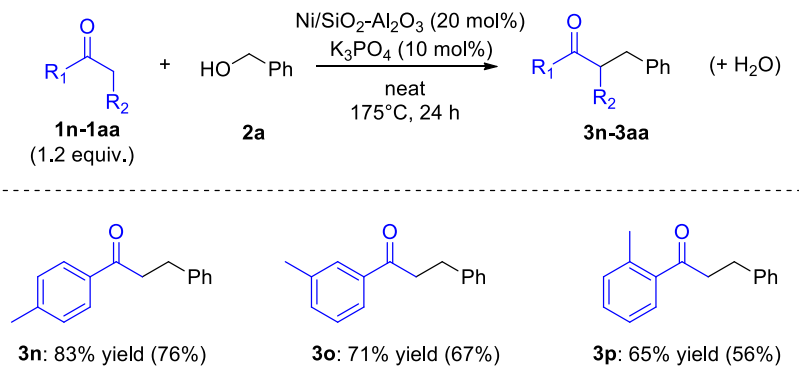
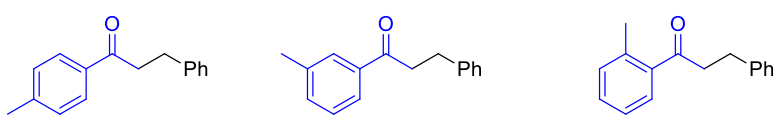<smiles>COc1ccc(C(=O)CCc2ccccc2)cc1</smiles>

3t: $15 \%$ yield<smiles>CC(Cc1ccccc1)C(=O)c1ccccc1</smiles>

$3 \mathbf{w}: 6 \%$ yield<smiles>O=C(CCc1ccccc1)c1ccc(C(F)(F)F)cc1</smiles><smiles>CC(C)C(=O)CCc1ccccc1</smiles>

3u: $64 \%$ yield $(62 \%)$<smiles>O=C1c2ccccc2CCC1Cc1ccccc1</smiles>

$3 x$ : $56 \%$ yield $(38 \%)$
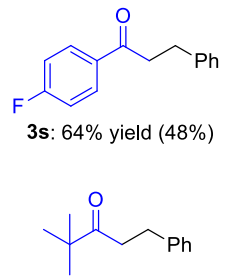

$3 v$ : $52 \%$ yield $(44 \%$

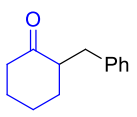

$3 y: 29 \%$ yield

Scheme 4. Alkylation of various ketones with benzyl alcohol. Reaction conditions: $\mathbf{1 m - 1 x}$ (11.6 mmol, 1.2 equiv.), $2 \mathrm{a}(9.7 \mathrm{mmol}), 65 \mathrm{wt} \% \mathrm{Ni} / \mathrm{SiO}_{2}-\mathrm{Al}_{2} \mathrm{O}_{3}(20 \mathrm{~mol} \%), \mathrm{K}_{3} \mathrm{PO}_{4}(10 \mathrm{~mol} \%$ ), neat, $175^{\circ} \mathrm{C}, 24 \mathrm{~h}$. Yield of $\mathbf{3 m}-\mathbf{3 x}$ were determined by ${ }^{1} \mathrm{H}$ NMR with mesitylene as internal standard, isolated yield in parentheses. ${ }^{a}$ Combined yield of saturated and unsaturated species. 
For acetophenones, the same trend is observed as for benzyl alcohols: para-electron-donating groups (3n, 3q) seem to favor the reaction whereas a para-electron withdrawing group (3r) afforded a moderate yield. Electron-donating substituents increase the nucleophilicity of the enolate intermediate, thus leading to improved yields, and vice-versa for electronwithdrawing substituents. Again, the reaction yield decreases from para- to ortho-methyl acetophenones (from $3 n$ to $3 p$ ). This phenomenon is probably due to the steric hindrance of the methyl group, which can constrain the transition state of the attack of the enolate onto the aldehyde. Halogen-substituted acetophenones were next tested. The use of parafluoroacetophenone resulted in moderate yield (3s) while a lower yield was obtained with para-chloroacetophenone (3t). In that case, dechlorination of both starting material and desired product through nickel catalysis was observed as the major reaction. Aliphatic ketones such as 2-octanone and pinacolone afforded moderate yields ( $3 \mathbf{u}$ and $\mathbf{3 v}$ ), probably due to their lower reactivity. More hindered ketones were tested: propiophenone gave very low yield (3w) whereas $\alpha$-tetralone afforded the desired product in moderate yield (3x), showing that rigidity of the $-\mathrm{CH}_{2}$ - ketones seems to favor the reaction. Cyclohexanone gave low yield ( $3 y$ ) and no double-alkylation was observed under these conditions. The $\alpha$-benzylation of acetone could be performed, giving the desired product (3z) in moderate yield, and only traces of $\alpha, \alpha^{\prime}$-benzylation were observed. In order to evaluate the compatibility of a conjugated ketone in our conditions, mesityl oxide was engaged into reaction. As the $\mathrm{C}=\mathrm{C}$ bond partially underwent reduction, two products were formed. The desired product and its reduced form were obtained in $9 \%$ and $24 \%$ yield respectively.

Other more challenging substrates, containing reducible functions were tested, such as 4-acetoxyacetophenone, 4acetylbenzylcyanide and $p$-nitro compounds. Unfortunately, the desired products were not obtained in these cases.

The recyclability of the catalyst has been studied over 5 runs for the $\alpha$-alkylation of acetophenone by benzyl alcohol in the optimized conditions (Figure 1). During optimization of the recycling procedure (see $\mathrm{SI}$ for the detailed description of the recycling procedure), it has been shown that addition of the base is required in order to maintain a high yield (without addition of base, the reaction afforded the product in $60 \%$ yield after a new run).

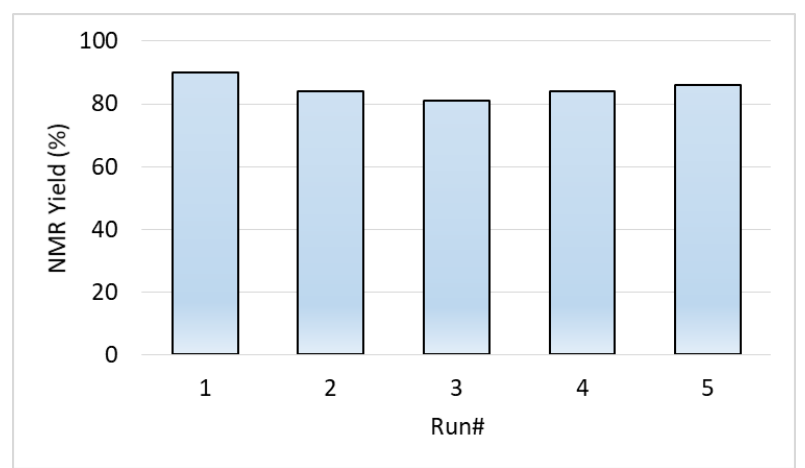

Figure 1. Recycling study of the catalyst (yield of $\mathbf{3 a}$ is determined by ${ }^{1} \mathrm{H}$ NMR with mesitylene as internal standard).
Over 5 runs, no significant decrease of the yield was observed, thus showing that the nickel on silica-alumina catalyst can be recycled without significant loss of activity. Potential leaching of the catalyst was tested by removing the catalyst (filtration) from the hot reactive mixture after one hour of reaction (same reagents and conditions as for the recycling) and reengaging the filtrate in reaction for 23 hours more. No evolution of the yield of $\mathbf{3 a}$ and conversion of benzyl alcohol was observed, thus showing that the removal of the catalyst stopped the reaction. Consequently, no leaching occurs during the reaction (see Supporting Information for more details).

The nickel supported on silica-alumina catalyst has been characterized before and after one reaction cycle, in order to study not only the characteristics of the pristine catalysts, but also the potential modifications during reaction. Images obtained by scanning electron microscopy (SEM) showed particle sizes between 100 and $200 \mathrm{~nm}$ for both fresh and used catalyst (Figure 2). Particle morphology, size and homogeneity are similar in both cases. Energy dispersive X-ray spectroscopy (EDS) coupled to the SEM showed a homogeneous dispersion of the different elements of the catalyst within the resolution of the measurement. Specific surface area was measured by the Brunauer-Emmett-Teller (BET) method using nitrogen as the gas vector. The specific surface area of the fresh catalyst was found to be $171 \mathrm{~m}^{2} / \mathrm{g}$ (commercial provider indicate $190 \mathrm{~m}^{2} / \mathrm{g}$ ) whereas the BET surface area of the catalyst after one use increased to $214 \mathrm{~m}^{2} / \mathrm{g}$.

Powder X-ray diffraction ( $\mathrm{XXRD)}$ spectra of fresh and used catalyst look identical (a sample spectrum is shown in Fig SI-1). For both types of samples, nickel is found in both oxidized (NiO, cubic structure, JCPDS\# 01-089-3080) and metal forms (Ni, cubic structure, JCPDS\# 01-071-3740). Silica was observed in quartz form ( $\mathrm{SiO}_{2}$, JCPDS\# 00-001-0649).

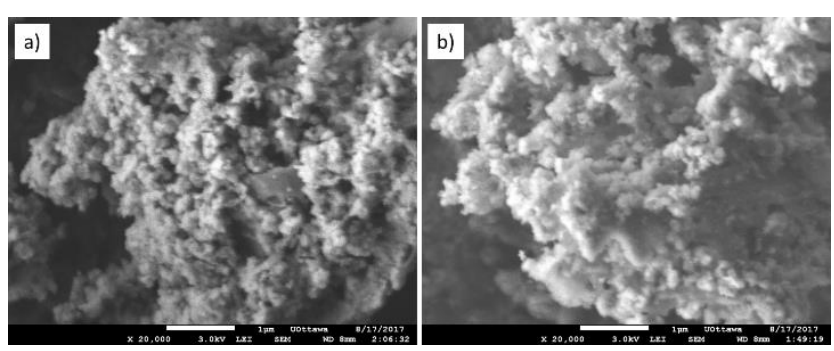

Figure 2. SEM images of fresh and used $\mathrm{Ni} / \mathrm{SiO}_{2}-\mathrm{Al}_{2} \mathrm{O}_{3}$ catalyst.

The oxidation state of nickel, which is believed to be critical for reaction activation, was also probed by $\mathrm{X}$-ray photoelectron spectroscopy (XPS).

The XP spectrum of the fresh $\mathrm{Ni} / \mathrm{SiO}_{2}-\mathrm{Al}_{2} \mathrm{O}_{3}$ catalyst is shown in Figure 3 (trace a). The survey indicates the presence of $\mathrm{Ni}, \mathrm{Si}, \mathrm{Al}$ and $\mathrm{O}$, with no other elemental impurities. In order to identify the nickel species present, we obtained high resolution spectra of the $\mathrm{Ni} 2 \mathrm{p}$ region (note that the $\mathrm{O} 1 \mathrm{~s}$ region is not readily usable due to the presence of the oxide support). Fitting the $\mathrm{Ni}$ $2 p$ region is complicated by the presence of multiple satellite peaks which are present for each possible species and which overlap with the $2 p$ doublet, ${ }^{39,40}$ particularly in small particles and when layers are present. ${ }^{41,42}$ Following the fitting 
procedure outlined by Biesinger ${ }^{43,44}$ to determine the nickel environment, three species are observed, namely metallic nickel, nickel oxide and nickel hydroxide. An example of the fitted spectrum is shown if Fig SI-2 for the fresh catalyst. Because the XPS measurements are intrinsically surface sensitive, this would indicate that the nickel catalyst is covered by an oxide and a hydroxide layer. It is important to note here that within the resolution of the XPS measurements, no distinction was made between $\mathrm{Ni}(\mathrm{OH})_{2}$ and $\mathrm{NiOOH}$. The typical interpretation is that the nickel catalyst, exposed to air, forms a surface bilayer with $\mathrm{Ni}(\mathrm{OH})^{2}$ underlaid by $\mathrm{NiO} .45$

A comparison of the fresh and used catalyst shows only slight shifts in the peaks that can be quantified based on the three species present (Figure 3). The fraction of metal:oxide:hydroxide species for the fresh catalyst is 2:25:73, while for the used catalyst the ratio is $2: 13: 85$. That is, more of the oxide was transformed to hydroxide. In contrast, a reduction of the fresh catalyst yields more metal, as expected, but only in detriment of the oxide layer (ratio 4:22:74). The oxide layer was also observed by XRD, as discussed above, however the hydroxide layer appears to be amorphous, since no corresponding diffractions peaks were observed. To test for the presence of hydroxide species directly, FTIR measurements were performed (Figure 4).
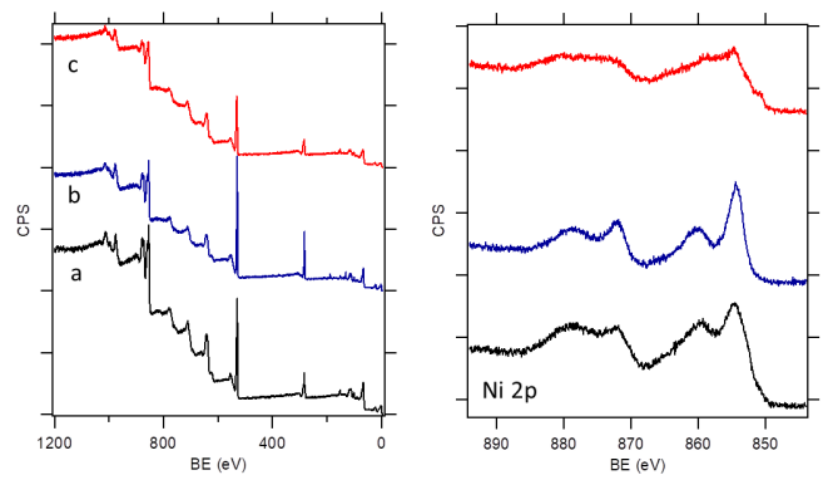

Figure 3. XPS spectra of the catalyst: a) fresh, b) used, c) reduced (black, blue and red in the color figure). Spectra are offset for clarity. Left panel shows the survey where only the expected elements are observed. Right panel show high resolution spectra of the $\mathrm{Ni}$ $2 p$ region.

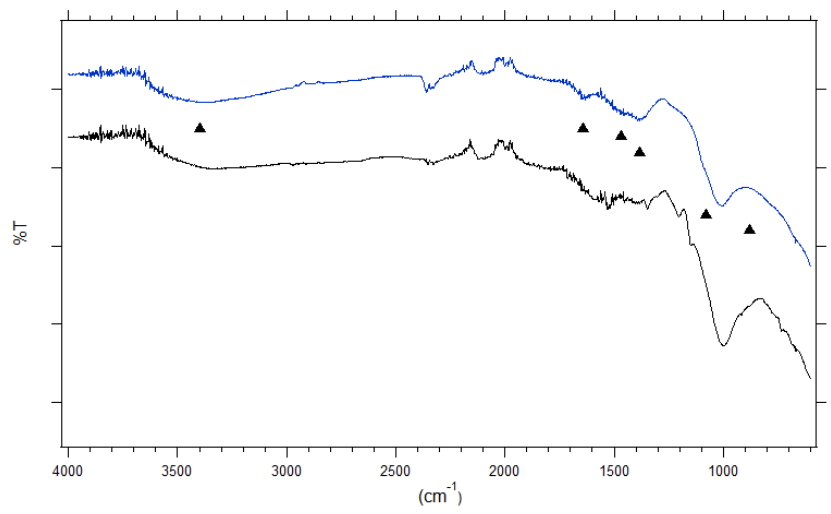

Figure 4. FTIR spectrum of fresh (top) and used (bottom) $\mathrm{Ni} / \mathrm{SiO}_{2}-\mathrm{Al}_{2} \mathrm{O}_{3}$ catalyst.
The characteristic sharp peak of $\beta-\mathrm{Ni}(\mathrm{OH})_{2}$ at $\sim 3640 \mathrm{~cm}^{-1}$ is not present. Instead, the IR spectrum of fresh catalyst shows the characteristic peaks observed for amorphous or $\alpha-\mathrm{Ni}(\mathrm{OH})_{2}$, namely i) a broad peak for the $\mathrm{OH}$ stretching modes of absorbed water at $3400 \mathrm{~cm}^{-1}$ with the corresponding bending modes at $\sim 1600 \mathrm{~cm}^{-1}$, and ii) the two peaks associated with the bending modes of lattice $\mathrm{OH}$ at $\sim 1390$ and $1490 \mathrm{~cm}^{-1} \cdot{ }^{[42,45,46]}$ Note that while the IR active modes of $\alpha-\mathrm{Ni}(\mathrm{OH})_{2}$ at $\sim 390, \sim 470$ and $\sim 650$ $\mathrm{cm}^{-1}$ are not measured in the standard FTIR experiment, the combination bands at $\sim 840$ and $1050 \mathrm{~cm}^{-1}$ are visible. The spectrum for the used catalyst shows the same peaks with the addition of small peaks associated with organic residues from the reaction environment. Characterization of the $\mathrm{Ni} / \mathrm{SiO}_{2}-\mathrm{Al}_{2} \mathrm{O}_{3}$ catalyst before and after use, as well as its stability during recycling tests suggest that the active surface of the catalyst is composed by amorphous $\mathrm{Ni}(\mathrm{OH})_{2}$ and the support in contact with the neat reagents.

\section{Conclusions}

In conclusion, we have demonstrated that acetophenone could be alkylated with benzyl alcohol through a borrowing hydrogen methodology using $\mathrm{Ni} / \mathrm{SiO}_{2}-\mathrm{Al}_{2} \mathrm{O}_{3}$ as a cheap heterogeneous catalyst. Advantageously, the reaction occurs under solventfree conditions and requires only a catalytic amount of base. Under these conditions, the corresponding alkylated acetophenone was obtained with $93 \%$ isolated yield. The optimized conditions were then applied to a wide range of ketones and alcohols and the desired products were obtained with $18-86 \%$ isolated yields (26 examples). Satisfyingly, $\mathrm{Ni} / \mathrm{SiO}_{2}-$ $\mathrm{Al}_{2} \mathrm{O}_{3}$ could be recycled over 5 runs without significant loss of activity.

\section{Conflicts of interest}

There are no conflicts to declare.

\section{Acknowledgements}

The authors thank the Ministère de l'Enseignement Supérieur, de la Recherche et de l'Innovation (MESRI) for a Ph.D. grant to A. C. and the LIA FUN-CAT for financing his research stay in the University of Ottawa. J. B. G. thanks the Natural Sciences and Engineering Research Council of Canada for funding (NSERC grant RGPIN 2014-261560).

\section{Notes and references}

1 D. Caine, in Comprehensive Organic Synthesis, Vol. 3, (Eds.: B. M. Trost and I. Fleming), Pergamon, Oxford, 1991, pp. 1-63.

2 Modern Carbonyl Chemistry (Ed.: J. Otera), Wiley-VCH, Weinheim, 2000.

3 A. Corma, J. Navas, M. J. Sabater, Chem. Rev. 2018, 118, 14101459.

4 Y. Obora, Top. Curr. Chem. (Z) 2016, 374, 261.

5 F. Huang, Z. Liu, Z. Yu, Angew. Chem. Int. Ed. 2016, 55, 862875.

6 K. Shimizu, Catal. Sci. Technol. 2015, 5, 1412-1427. 
7 C. S. Cho, B. T. Kim, T.-J. Kim, S. C. Shim, Tetrahedron Lett. 2002, 43, 7987-7989.

8 R. Martínez, D. J. Ramón, M. Yus, Tetrahedron 2006, 62, 89889001.

9 T. Kuwahara, T. Fukuyama, I. Ryu, Org. Lett. 2012, 14, 47034705.

10 J. Alós, T. Bolaño, M. A. Esteruelas, M. Oliván, E. Oñate, M Valencia, Inorg. Chem. 2014, 53, 1195-1209.

11 S.-Y. Liu, L.-Y. Xu, C.-Y. Liu, Z.-G. Ren, D. J. Young, J.-P. Lang, Tetrahedron 2017, 73, 2374-2381.

12 K. Taguchi, H. Nakagawa, T. Hirabayashi, S. Sakaguchi, Y. Ishii, J. Am. Chem. Soc. 2004, 126, 72-73.

13 J. Li, W. Zhang, F. Wang, M. Jiang, X. Dong, W. Zhao, Chin. J. Chem. 2012, 30, 2363-2366.

14 C. Xu, X.-M. Dong, Z.-Q. Wang, X.-Q. Hao, Z. Li, L.-M. Duan, B.M. Ji, M.-P. Song, J. Organomet. Chem. 2012, 700, 214-218.

15 D. Wang, K. Zhao, P. Ma, C. Xu, Y. Ding, Tetrahedron Lett 2014, 55, 7233-7235.

16 P. Liu, R. Liang, L. Lu, Z. Yu, F. Li, J. Org. Chem. 2017, 82, 19431950.

17 X. Yu, Q. Y. Wang, Q. J. Wu, D. W. Wang, Russ. J. Gen. Chem. 2016, 86, 178-183.

18 M. L. Buil, M. A. Esteruelas, J. Herrero, S. Izquierdo, I. M. Pastor, M. Yus, ACS Catal. 2013, 3, 2072-2075.

19 Y. Yang, A. Qin, K. Zhao, D. Wang, X. Shi, Adv. Synth. Catal. 2016, 358, 1433-1439.

20 P. Piehl, M. Peña-López, A. Frey, H. Neumann, M. Beller, Chem. Commun. 2017, 53, 3265-3268.

21 S. Elangovan, J.-B. Sortais, M. Beller, C. Darcel, Angew. Chem. Int. Ed. 2015, 54, 14483-14486.

22 C. Seck, M. D. Mbaye, S. Coufourier, A. Lator, J.-F. Lohier, A. Poater, T. R. Ward, S. Gaillard, J.-L. Renaud, ChemCatChem 2017, 9, 4410-4416.

23 M. Peña-López, P. Piehl, S. Elangovan, H. Neumann, M. Beller, Angew. Chem. Int. Ed. 2016, 55, 14967-14971.

24 G. Zhang, J. Wu, H. Zeng, S. Zhang, Z. Yin, S. Zheng, Org. Lett. 2017, 19, 1080-1083.

25 C. S. Cho, J. Mol. Catal. A: Chem. 2005, 240, 55-60.

26 G. Xu, Q. Li, J. Feng, Q. Liu, Z. Zhang, X. Wang, X. Zhang, X. Mu, ChemSusChem 2014, 7, 105-109.

27 M. S. Kwon, N. Kim, S. H. Seo, I. S. Park, R. K. Cheedrala, J. Park Angew. Chem. Int. Ed. 2005, 44, 6913-6915.

28 Y. M. A. Yamada, Y. Uozumi, Org. Lett. 2006, 8, 1375-1378.

29 J.-S. Jang, M.-S. Kwon, H.-G. Kim, J.-W. Park, J.-S. Lee, Bull. Korean Chem. Soc. 2012, 33, 1617-1621.

30 M. Bai, H. Xin, Z. Guo, D. Guo, Y. Wang, P. Zhao, J. Li, Appl. Surf. Sci. 2017, 391, Part B, 617-626.

31 S. K. Jana, Y. Kubota, T. Tatsumi, Stud. Surf. Sci. Catal., 2007, 165, 701-704.

32 S. Pei Shan, T. T. Dang, A. M. Seayad, B. Ramalingam, ChemCatChem 2014, 6, 808-814.

33 M. Dixit, M. Mishra, P. A. Joshi, D. O. Shah, Catal. Commun. 2013, 33, 80-83.

34 F. Alonso, P. Riente, M. Yus, Synlett 2007, 1877-1880.

35 F. Alonso, P. Riente, M. Yus, Eur. J. Org. Chem. 2008, 49084914.

36 K. Hisamura, N. Yamanaka, T. Sugitani, JP 2002-173460, 2002.

37 M. Guerbet, C. R. Hebd. Seances Acad. Sci. 1899, 128, 1002 1004.

38 K. Ding, S. Xu, R. Alotaibi, K. Paudel, E. W. Reinheimer and J. Weatherly, J. Org. Chem., 2017, 82, 4924-4929.

39 M. Tomellini, J. Chem. Soc. Faraday Trans. 1 1988, 84, 35013510.

40 S. Uhlenbrockt, C. Scharfschwerdtt, M. Neumannt, G. Illing, H.-J. Freund, J. Phys. Condens. Matter 1992, 4, 7973-7978.

41 J. Wang, D. Teschner, Y. Yao, X. Huang, M. Willinger, L. Shao, R. Schlögl, J. Mater. Chem. A 2017, 5, 9946-9951.

42 D. S. Hall, D. J. Lockwood, S. Poirier, C. Bock, B. R. MacDougall, J. Phys. Chem. A 2012, 116, 6771-6784.
43 M. C. Biesinger, B. P. Payne, L. W. M. Lau, A. Gerson, R. S. C. Smart, Surf. Interface Anal. 2009, 41, 324-332.

44 M. C. Biesinger, http://www.xpsfitting.com (accessed Oct 6 2017).

45 D. S. Hall, D. J. Lockwood, C. Bock, B. R. MacDougall, Proc. R. Soc. A Math. Phys. Eng. Sci. 2014, 471, 20140792.

46 S. Le Bihan, M. Figlarz, J. Cryst. Growth 1972, 13/14, 458-461. 